\title{
EVALUATION OF PREVALENCE OF DIABETIC FOOT ULCER AND ITS RELATED FACTORS IN DIABETIC PATIENTS ADMITTED TO KHATAM-OL-ANBIA HOSPITAL IN SHOUSHTAR DURING 2015-2016: A RETROSPECTIVE STUDY
}

\author{
Mostafa Madmoli ${ }^{1}$, Fatemeh Rostami2 ${ }^{*}$, Nastaran Mirsami Yazdi ${ }^{3}$, Ahmad Mosavi ${ }^{4}$, Shahram Baraz $^{5}$ \\ ${ }^{1}$ Emergency Medical Technician, Dezful University of Medical Sciences, Dezful, Iran; \\ ${ }^{2 *}$ Bushehr University of Medical Sciences, Bushehr, Iran; \\ ${ }^{3,4}$ Dezful University of Medical Sciences, Dezful, Iran; \\ ${ }^{5}$ Nursing Care Research Center in Chronic Diseases, School of Nursing and Midwifery, Ahvaz, Jundishapur \\ University of Medical Sciences, Ahvaz, Iran;
}

*Corresponding author Fatemeh Rostami, email: fa.rostami@bpums.ac.ir;

Received May, 2018; Accepted May, 2018; Published June, 2018;

doi: https://doi.org/10.31407/ijees8314

UOI license: http://u-o-i.org/1.01/ijees/54099599

\begin{abstract}
Background: Diabetes is a chronic disease that results in disruption of the production and function of insulin in the body. Foot ulcer is a major complication of diabetes mellitus with high morbidity, mortality and related costs. This retrospective study was conducted to investigate Evaluation of prevalence of diabetic foot ulcer and its related factors in diabetic patients admitted to Khatam-ol-Anbia Hospital in Shoushtar during 2015-2016. Methods: In this retrospective cross-sectional descriptive study, the data were analyzed from a report of diabetic patients referring to Khatam-ol-Anbia Hospital in Shoushtarduring 2015-2016 which included 1257 patients with diagnosis and history of diabetes that they were extracted from them and the required information was collected through a checklist of researcher-made files. The inclusion criteria for all diabetic patients were Type One and Two. Pregnant diabetes, cases without diabetes and incomplete cases $(n=213)$ were excluded. Data were then entered into SPSS software version 17 and analyzed by descriptive statistics, Chi-square, Pearson's chi-square test, ANOVA, and nonparametric tests such as Mann-Whitney. The significance level was considered as $\mathrm{P}<0.05$. Results: The sample included 1257 individuals with type 1 and type 2 diabetes with an average age of $58.6 \pm 17.6$. Of these, $43.2 \%$ were male and the rest were female and $18.6 \%$ were type 1 diabetes and the rest were type 2 diabetes. The prevalence of lower limb ulcers in the last two years was $9.1 \%$ (115). There was a significant relationship between the type of diabetes and the prevalence of lower limb ulcer in the past and before the last two years $(\mathrm{P}<0.05)$. Conclusion: The results of this study indicate that the prevalence of diabetic foot ulcer is much higher than other studies. It is recommended that diabetic foot care training, blood glucose control, proper diet and other necessary training for diabetics should be aimed at preventing and reducing diabetic foot ulcers to nurses who are the first line of the treatment team and They play a vital role in the prevention and care of diabetic foot, and nutritionists who play a vital role in educating the proper diet of patients, to be presented.
\end{abstract}

Keywords: Diabetic foot, foot ulcers, diabetic patients, prevalence 